\title{
A FIFTY-TWO-WEEK CHRONIC TOXICITY STUDY OF HALOPREDONE ACETATE (THS-201) IN DOGS
}

\author{
Kazumasa YAMASHITA, Hideaki YADA, Kenji IRIMURA, \\ Taiji HAYASHI, Hidenobu MORINAGA \\ and Ken'ichi MORITA \\ Research Laboratory, Taiho Pharmaceutical Co., Ltd., \\ 224-2 Ebisuno Hiraishi Kawauchi-cho, Tokushima, Japan \\ Accepted February 10, 1986
}

\begin{abstract}
In order to evaluate the long-term-safety of halopredone acetate (THS-201: $17 \alpha, 21$-diacetoxy-2-bromo-6 $\beta, 9 \alpha$-difluoro-11 $\beta$-hydroxy-1, 4 pregnadiene-3, 20-dione), a 52 -week chronic toxicity study was performed on the basis of its local accumulation in dogs. In doses of $0.1,0.5$ and $2.5 \mathrm{mg} / \mathrm{kg}$, THS-201 was injected into the right knee joint in both sexes of dogs every 2 weeks for 39 weeks and withdrawn for 13 weeks.

In this study, the below slight local changes were observed in both sexes of dogs treated with $2.5 \mathrm{mg} / \mathrm{kg} / 2$ weeks of THS-201 : focal loss of hair of the injection site, lesser stain in cartilage matrix of articular cartilage and meniscus in light microscopic examinations, and irregular thickness and elongation of collagen fibers, roughness of fibrous density and decrement of proteoglycans in electron microscopic examinations. In conclusion, systemic adverse effects were not observed in any dogs treated with THS-201.
\end{abstract}

Key words : Halopredone acetate (THS-201), corticosteroid, chronic toxicity, dogs.

\section{INTRODUCTION}

THS-201 (17 $\alpha, 21$-diacetoxy-2-bromo-6 $\beta, 9 \alpha$-difluoro-11 $\beta$-hydroxy-1, 4-pregnadiene-3, 20-dione), a new anti-inflammatory corticosteroid, was synthesized by Toscano et al. (1977), and has been developed for clinical use of intra-articular corticosteroid by Taiho Pharmaceutical Co., Ltd..

Mizushima et al. (1980) and Miyake et al. (1981) reported that in case of its topical administration the local anti-inflammatory effects lasted much longer, and that the systemic effects were very slight in animals because of its local accumulation. The low toxicities of

連絡先：雪771-01 徳島市川内町平石字夷野 224-2

大鵬薬品工業株式会社・研究開発本部研究部山下和 正 


\section{Kazumasa YAMASHITA et al.}

THS-201 in dogs have been reported in previous paper of its 13-week subacute toxicity study (Yamashita et al., 1984). These reports on laboratory investigations suggested that THS-201 had the long activity in the injection site, and that the local and systemic toxicities were low. However, the long-term toxicity of THS-201 remains to be investigated. In order to evaluate the long-term-safety of THS-201, a fifty-two-week chronic toxicity study on this compound was carried out in dogs. In the present paper, the details are mentioned.

\section{MATERIALS AND METHODS}

1) Compound:

THS-201 (Fig. 1) was supplied from Dainippon Inki Kagaku Co., Ltd. (Tokyo, Japan). THS-201 was suspended in a solvent which contained $0.25 \%$ Tween $80,0.35 \% \mathrm{CMC}-\mathrm{Na}$ and $0.7 \%$ benzylalcohol, and the concentration of THS-201 in the solvent were adjusted in $0.1,0.5$ and $2.5 \%(\mathrm{~W} / \mathrm{V})$. These suspensions were sterilized using $105^{\circ} \mathrm{C}$ steam for $60 \mathrm{~min}$.

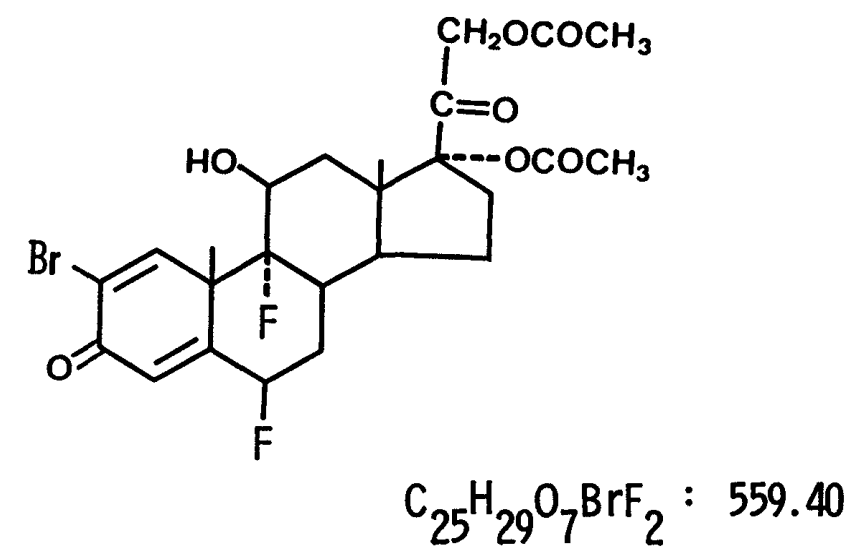

$17 \alpha, 21$-diacetoxy-2-bromo-6 $\beta, 9 \alpha$-difluoro- $11 \beta-$ hydroxy-1,4-pregnadiene-3,20-dione

(Halopredone acetate)

Fig. 1 Chemical structure of THS-201

2) Animals :

Five-month-old male and female beagle dogs which were purchased from Laboratory Research Enterprises (L. R. E., U. S. A) were used after complete physical examinations and quarantine for about 1 month.

Forty-eight dogs including 24 males weighing $8.21-10.05 \mathrm{~kg}$ and 24 females weighing 6.86-9.77 $\mathrm{kg}$ at 6 month of age, were divided randomly into 4 groups in each sex by a computor system. 
Toxicity study of halopredone acetate in dogs

They were housed in individual stainless-steel-cages in air, temperature $\left(23 \pm 1^{\circ} \mathrm{C}\right)$, and humidity $(55 \pm 10 \%)$ controlled rooms. Three hundred $\mathrm{g} / \mathrm{dog} /$ day of commercial dog chow (CD-5, Clea Japan Inc.) were given to the dog, and water ad libitum throughout the experiment.

3) Administration :

Table 1 summarized the experimental design of each group in this study. THS-201 suspended solution was injected every 2 weeks into the right knee joint in a volume of 0.1 $\mathrm{ml} / \mathrm{kg}$. The doses of THS-201 were determined on the basis of the results of 13-week subacute toxicity study in dogs. To the control dogs, the solvent lacking THS-201 was injected in an equivalent volume of $0.1 \mathrm{ml} / \mathrm{kg}$.

Table 1 Experimental design of chronic toxicity study in both sexes of dogs

\begin{tabular}{|c|c|c|c|c|c|c|c|c|}
\hline & & & & & THS-20 & $(\mathrm{mg} / \mathrm{kg})$ & & \\
\hline & & & & & & & & \\
\hline & M & $\mathrm{F}$ & M & $F$ & M & F & M & $\mathrm{F}$ \\
\hline & $00001^{*}$ & 10001 & 00007 & 10007 & 00013 & 10013 & 00019 & 10019 \\
\hline 39 week & 00002 & 10002 & 00008 & 10008 & 00014 & 10014 & 00020 & 10020 \\
\hline autopsy & 00003 & 10003 & 00009 & 10009 & 00015 & 10015 & 00021 & 10021 \\
\hline & 00004 & 10004 & 00010 & 10010 & 00016 & 10016 & 00022 & 10022 \\
\hline 52 week & 00005 & 10005 & 00011 & 10011 & 00017 & 10017 & 00023 & 10023 \\
\hline autopsy & 00006 & 10006 & 00012 & 10012 & 00018 & 10018 & 00024 & 10024 \\
\hline
\end{tabular}

M : Male F: Female * Animal No.

4) Observations :

General conditions and symptoms (twice a day), food consumption (daily), water consumption (every 4 weeks) and body weight (weekly in 0-26 weeks, every 2 weeks in 27-52 weeks) were investigated and recorded throughout the experiment.

5) Clinical laboratory examinations:

Table 2 showed the items and methods of clinical laboratory examinations in this study.

The urinary, fecal, hematological and biochemical parameters were examined at the 0 , 26-27 and 37-39 week in the administered groups and 50-52 week in the withdrawal groups.

Urine samples were obtained by use of metabolic cages. The samples for qualitative tests were obtained immediately after the urination, and the samples for quantitative tests were collected for 18 hours.

Fecal samples were obtained after the observation of general conditions and symptoms. 
Kazumasa YAMASHITA et al.

Table 2 Items and methods for hematological, biochemical, urinary and fecal tests

\begin{tabular}{|c|c|c|c|}
\hline Test & Items & Abbreviation & Method \\
\hline \multirow[t]{20}{*}{ Hematology } & Erythrocyte & $\mathrm{RBC}$ & ELT-8 hematology analyzer \\
\hline & Hemoglobin & $\mathrm{Hb}$ & ELT-8 hematology analyzer \\
\hline & Hematocrit & $\mathrm{Ht}$ & ELT-8 hematology analyzer \\
\hline & Mean corpuscular volume & $\mathrm{MCV}$ & ELT-8 hematology analyzer \\
\hline & Mean corpuscular hemoglobin & $\mathrm{MCH}$ & ELT-8 hematology analyzer \\
\hline & Mean corpuscular hemoglobin concentration & n $\mathrm{MCHC}$ & ELT-8 hematology analyzer \\
\hline & Reticulocyte & Retic. & Microscopic cell count \\
\hline & Luekocyte & WBC & ELT-8 hematology analyzer \\
\hline & Differen tial luekocyte count & & Microscopic cell count \\
\hline & Meta myelocyte & Meta & (Wright-Giemsa stain) \\
\hline & Neutrocyte-Stab form & $\mathrm{N}-\mathrm{St}$ & \\
\hline & Neutrocyte-Segmented & $\mathrm{N}-\mathrm{Seg}$ & \\
\hline & Lymphocyte & Lym & \\
\hline & Atypical lymphocyte & A. Lym & \\
\hline & Monocyte & Mono & \\
\hline & Eosinophile & Eosino & \\
\hline & Platelet & PLAT & ELT-8 hematology analyzer \\
\hline & Prothrombin time & PT & Quick one-stage method \\
\hline & Activated partial thromboplastin time & APTT & Proctor and Rapaport method \\
\hline & Fibrinogen & FIB & Thrombin time method \\
\hline \multirow[t]{27}{*}{ Biochemistry } & Glutamic oxaloacetate transaminase & GOT & Hitachi-726 automatic analyzer \\
\hline & Glutamic pyruvate transaminase & $\mathrm{GPT}$ & Hitachi-726 automatic analyzer \\
\hline & Lactate dehydrogenase & LDH & Hitachi-726 automatic analyzer \\
\hline & Alkaline phosphatase & AlP & Hitachi-726 automatic analyzer \\
\hline & Cholinesterase & $\mathrm{ChE}$ & Hitachi-726 automatic analyzer \\
\hline & $\tau$-Glutamyltranspeptidase & $\tau-\mathrm{GTP}$ & Hitachi-726 automatic analyzer \\
\hline & Glucose & GLU & Hitachi-726 automatic analyzer \\
\hline & Non-esterified fatty acid & NEFA & ACA-ACOD method \\
\hline & Triglyceride & $\mathrm{TG}$ & Hitachi-726 automatic analyzer \\
\hline & Phospholipid & PL & Hitachi-726 automatic analyzer \\
\hline & Total cholesterol & T. cho & Hitachi-726 automatic analyzer \\
\hline & Free cholesterol & F. cho & Hitachi-726 automatic analyzer \\
\hline & Choresterol ester ratio & $\mathrm{EST} / \mathrm{T}$ & Calculation \\
\hline & Total protein & $\mathrm{TP}$ & Biuret method \\
\hline & Albumin & ALB & Calculation \\
\hline & Albumin-globulin ratio & $\mathrm{A} / \mathrm{G}$ & Electrophoresis and densitmetry \\
\hline & Total bilirubin & T. bil & Hitachi-726 automatic analyzer \\
\hline & Urea nitrogen & Urea $\mathrm{N}$ & Hitachi-726 automatic analyzer \\
\hline & Crea tinine & CRN & Hitachi-726 automatic analyzer \\
\hline & Uric acid & UA & Hitachi-726 automatic analyzer \\
\hline & Calcium & $\mathrm{Ca}$ & Hitachi-726 automatic analyzer \\
\hline & Inorganic phosphorus & IP & Hitachi-726 automatic analyzer \\
\hline & Sodium & $\mathrm{Na}$ & Ion-selective electrode method \\
\hline & Potassium & $\mathrm{K}$ & Ion-selective electrode method \\
\hline & Chloride & $\mathrm{Cl}$ & Coulometric tit rator method \\
\hline & Hepatic function test & ICG & Diagnogreen ${ }^{\mathrm{B}}$ injection \\
\hline & Renal function test & PSP & Phenolsulfonphtalein injection \\
\hline \multirow{10}{*}{$\begin{array}{l}\text { Urinary } \\
\text { (Fresh } \\
\text { voided) }\end{array}$} & Specific gravity & Spec. Grav. & Multistix $\mathrm{SG}^{\bar{B}}$ \\
\hline & $\mathrm{pH}$ & & Multistix $\mathrm{SG}^{\bar{\varepsilon}}$ \\
\hline & Protein & & Multistix $\mathrm{SG}^{\text {B }}$ \\
\hline & Glucose & & Multistix $\mathrm{SG}^{\bar{B}}$ \\
\hline & Ketone body & & Multistix $\mathrm{SG}^{\mathbb{8}}$ \\
\hline & Occult blood & & Multistix $\mathrm{SG}^{\mathrm{B}}$ \\
\hline & Urobilinogen & & Multistix $\mathrm{SG}^{\mathrm{B}}$ \\
\hline & Bilirubin & & Multistix $\mathrm{SG}^{\S}$ \\
\hline & Color & & \\
\hline & Sediment & & Microscope \\
\hline$(18 \mathrm{hrs}$ & Urine volume & & \\
\hline \multirow[t]{4}{*}{ accumulated) } & Osmotic Pressure & Osmo. Press. & Freezing point method \\
\hline & Sodium & $\mathrm{Na}$ & Ion-selective electrode method \\
\hline & Potassium & $\mathrm{K}$ & Ion-selective electrode method \\
\hline & Chloride & $\mathrm{Cl}$ & Coulometric $\leftrightarrow$ titrator method \\
\hline Fecal & Occult blood & & Guaiac method \\
\hline
\end{tabular}


Toxicity study of halopredone acetate in dogs

Blood samples for hematological and biochemical tests obtained via the accessory cephalic vein prior to the administration and feeding. Blood samples were immediately treated with an anti-coagulant EDTD-2K or $3.8 \%$ sodium citrate, and were centrifuged to separate the serum by a vacutainer-SST ${ }^{\circledR}$ (Becton-Dickinson, U. S. A.).

Hepatic and renal function tests were carried out at the 39 and 52 week. Thirty min. after the injection of $0.1 \mathrm{ml} / \mathrm{kg}$ of Indocianingreen (ICG) or Phenylsulphonphtaleine (PSP), the obtained samples were analyzed.

6) Ophthalmoscopic examination and electrocardiograms (ECG) :

Ophthalmoscopic examination and ECG tests were carried out at the 0, 38-39 and 51-52 week.

After local application of pupil dilating agent (Mydrin $\mathrm{P}^{\circledR}$, Santen Pharmaceutical Co., Ltd.), ophthalmoscopic examination was performed observing the appendages of the eye grossly or by Slit-lamp (SL-2, Kowa), and fundus oculi by funduscope (RC-2, Kowa).

ECG test was examined under the modes of bipolar standard limb leads of I, II and III and of augmented unipolar extremity leads of $\mathrm{aV}_{\mathrm{R}}, \mathrm{aV}_{\mathrm{L}}$ and $\mathrm{aV}_{\mathrm{F}}$ using a cardiometer (1E31, SAN-EI Sokki).

After completing the examinations at the 39 (39 week autopsy groups) and 52 (13 week withdrawal groups) week, the dogs were anesthetized by Ravonal ${ }^{\mathbb{E}}$ (Tanabe Pharmaceutical Co., Ltd.) and bled to death by cutting common carotid arteries. The main organs including pituitary, thyroids, adrenals, cerebrum, cerebellum, thymus, heart, lung, liver, stomach, kidneys, spleen, urinary bladder, pancreas, testes, prostate, ovaries and uterus were grossly observed, weighed and calculated the relative weight to body weight. The below general organs for pathological specimens were fixed in $10 \%$ buffered formalin, and stained with hematoxylin and eosin (H.E.): main organs, aorta, femoral vein, portal vein, mesenteric lymph node, bone marrow, sternum, lumbar vertebrae, femur, esophagus, duodenum, jejunum, ileum, cecum, colon, rectum, medulla oblongata, spinal cord, sciatic nerve, eye ball, femoral gracilis, skin, mammary gland, submaxillary glands, parotid glands, epididymides, knee joint (articular cartilage, meniscus, synovial tissue and joint capsule) and other lesions.

In addition, the specimens of articular cartilage and meniscus of knee joint were stained with Safranine-0 Fast Green iron hematoxylin (Safranine-0 stain) and observed under a light microscope.

8) Electron microscopy :

From the two dogs in each group, the tissues of liver, cortex of kidney and articular cartilage of right knee joint were sampled for the transfer electron microscopic (TEM) examination. Furthermore, from the respective two dogs in the control and the $2.5 \mathrm{mg} / \mathrm{kg} / 2$ weeks group of both sexes, the specimens of articular cartilage of right and left knee joint 
Kazumasa YAMASHITA et al.

were sampled for the scanning electron microscopic (SEM) examination.

The specimens sampled for electron microscopic examinations were fixed in a $2.5 \%$ glutaraldehyde solution for 2 hours, and were post-fixed in a $1.0 \% \mathrm{OsO}_{4}$ solution for 2 hours using $0.1 \mathrm{M}$ phosphate buffer $(\mathrm{pH} 7.4)$.

In addition, cartilaginous samples for TEM were stained with Safranine-0 (Shepard, N. et al., 1977).

After that, these were dehydrated in graded alcohol, exchanged to propylenoxide and embeded in Epock $812^{\mathbb{E}}$. The ultra-thin sections obtained from those were doubly stained with uranyl acetate and lead citrate for a purpose of examination with a TEM (H-500, Hitachi Ltd.).

For SEM examination, dehydrated samples were immersed into isoamylacetate, dried by critical point dryer (HCP-1, Hitachi Ltd.), coated with gold in a vaccum-evaporator (IB-2, Eiko Engineering), and were examined with a SEM (ISI-DS-130, Akashi Ltd.).

9) Statistics :

The data were analyzed by the one way lay out analysis of variance and multiple comparison (urinary qualitative test, fecal test, differential leukocyte count and reticulocyte were analyzed by Kruskal-Wallis test).

\section{RESULTS}

General conditions and symptoms :

All dogs in both sexes of the $2.5 \mathrm{mg} / \mathrm{kg} / 2$ weeks groups showed the focal loss of hair of the injection site from the 25 weeks after the initiation of the experiment. A male dog of the $2.5 \mathrm{mg} / \mathrm{kg} / 2$ weeks group showed the slight emaciation.

Body weight :

Fig. 2 and 3 showed the mean body weight changes in male and female dogs throughout the experiment.

Significant changes in mean body weights were not observed in any group in each time point throughout the experiment.

Individually, a male dog of the $2.5 \mathrm{mg} / \mathrm{kg} / 2$ weeks group and a female dog of the control group showed slight decrement of body weight gain.

Food and water consumption :

Significant changes in food and water consumptions were not observed in any group in each time point throughout the experiment.

Ophthalmoscopic examination and ECG test :

Significant changes were not observed in any group throughout the experiment.

Clinical laboratory examinations : 
Toxicity study of halopredone acetate in dogs

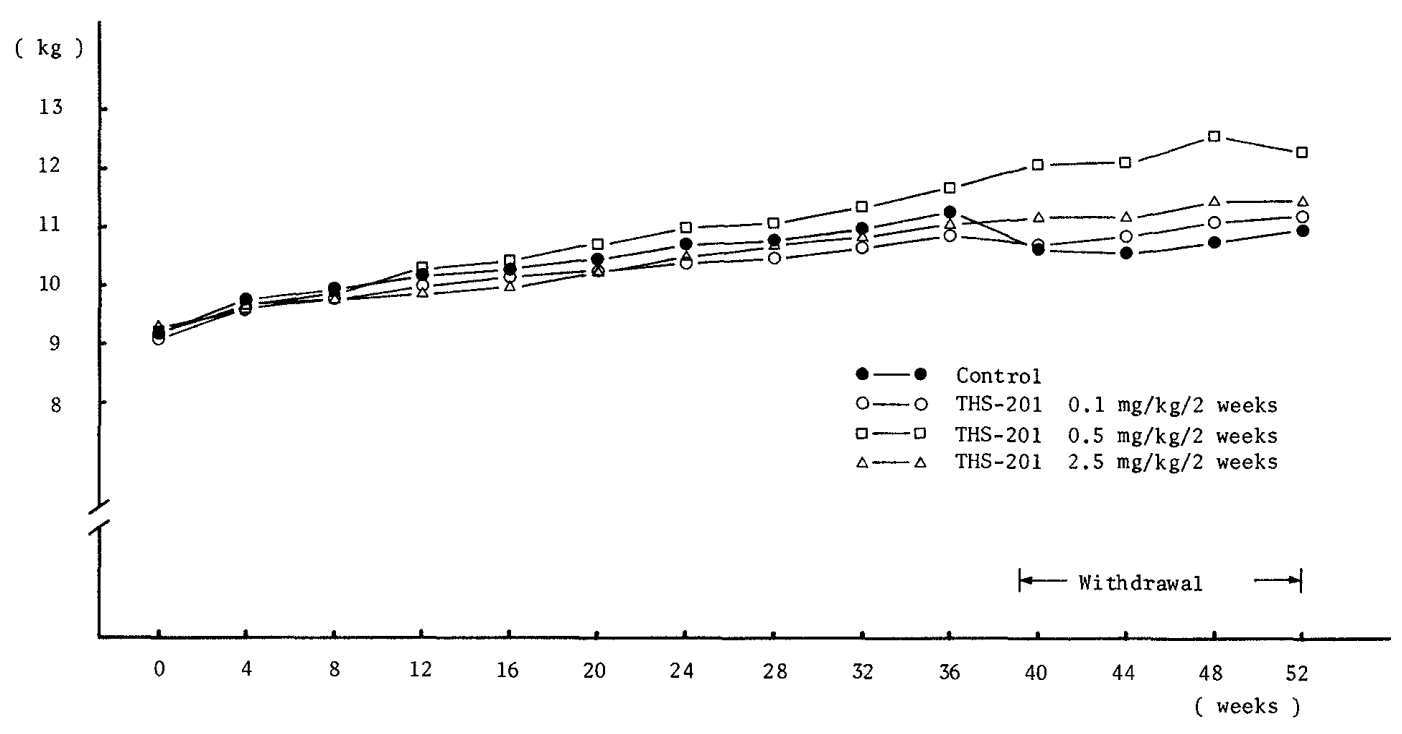

Fig. 2 Changes in mean body weight of male beagle dogs during the intraarticular administration of THS-201 for 39 weeks and the withdrawal period for 13 weeks

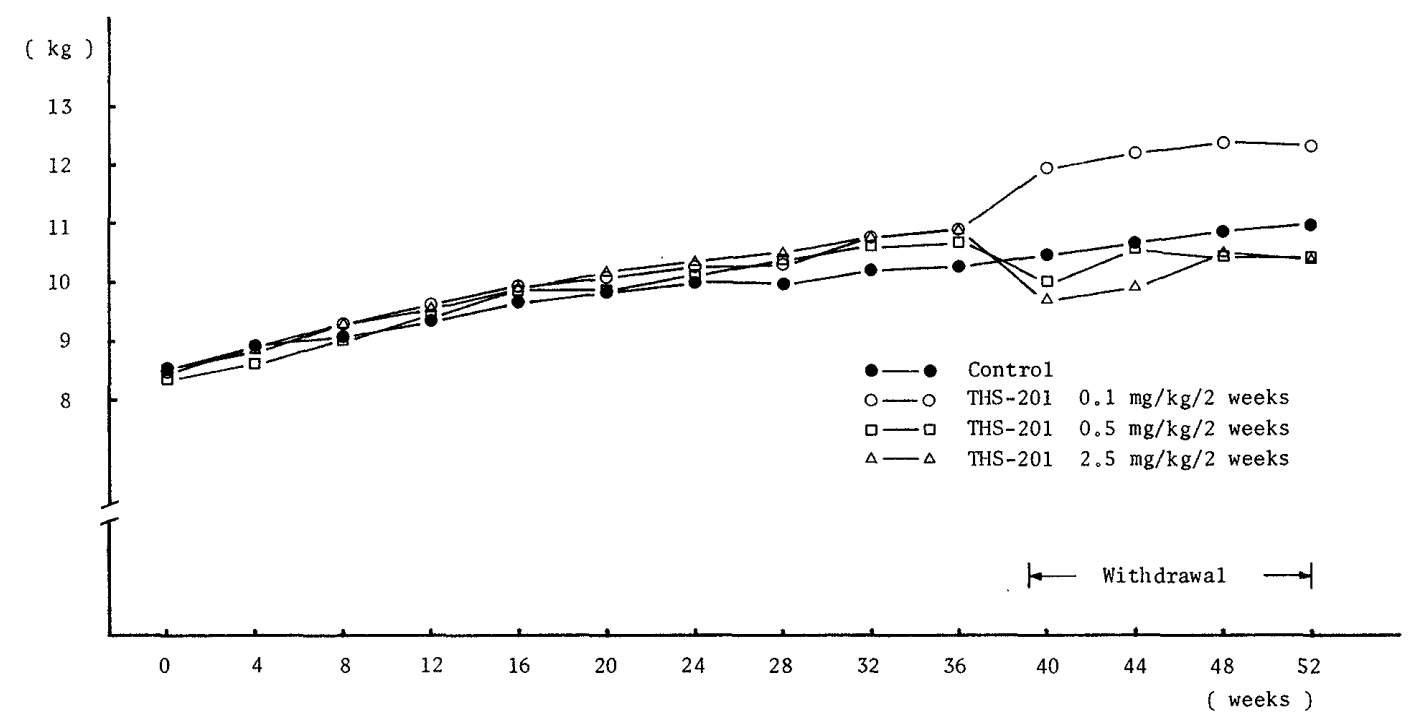

Fig. 3 Changes in mean body weight of female beagle dogs during the intra-articular administration of THS-201 for 39 weeks and the withdrawal period for 13 weeks

\section{1) Urinary tests}

Table 3 showed the results of the urinary tests at the 37 week in the experiment.

Increment in urine volume was observed in males of the $2.5 \mathrm{mg} / \mathrm{kg} / 2$ weeks group at the 26 week and males of the $0.5 \mathrm{mg} / \mathrm{kg} / 2$ weeks group at the 37 week. However, these values were within the normal ranges. 
Kazumasa YAMASHITA et al.

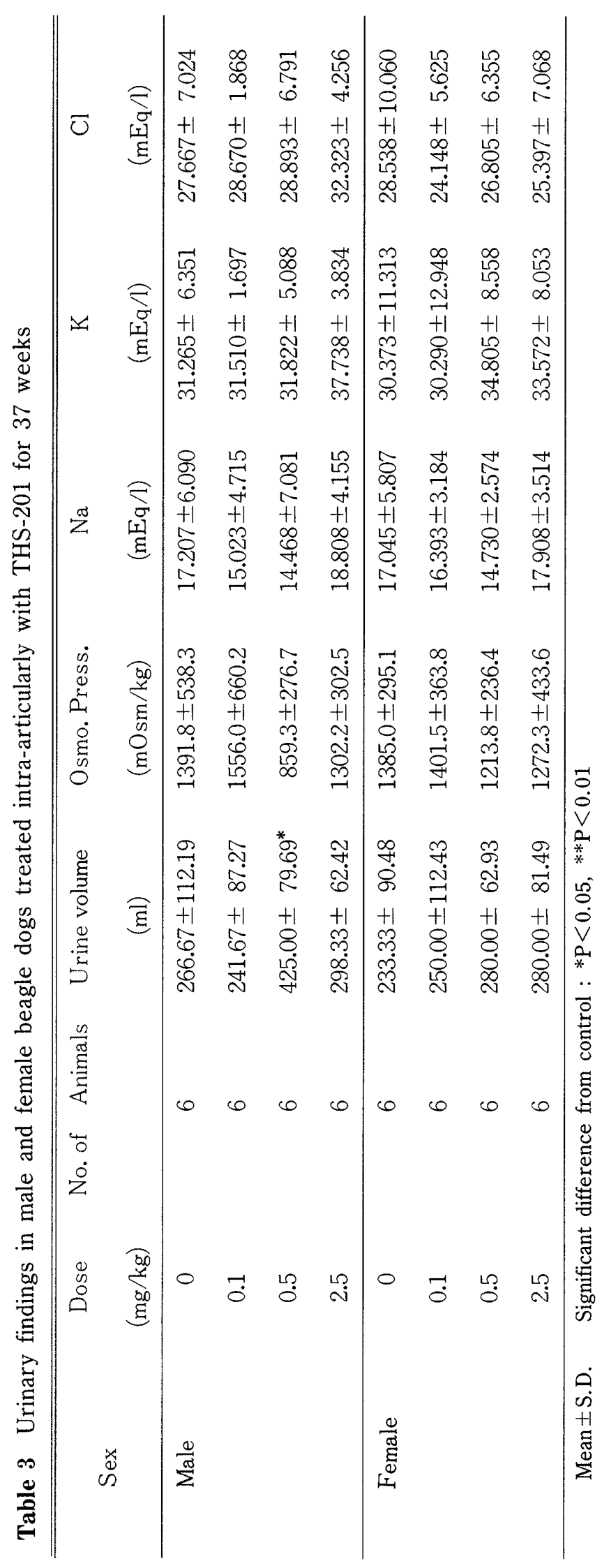


2) Fecal test

Significant changes were not observed in any group throughout the experiment.

3) Hematological tests

Table 4 showed the results of the hematological tests at the 39 week in the experiment.

Significant changes were not observed in any group throughout the experiment.

4) Biochemical tests

Table 5 showed the results of the biochemical tests at the 39 week in the experiment.

The GPT activity was slightly high in females of the $2.5 \mathrm{mg} / \mathrm{kg} / 2$ weeks group at the 39 week. However, this value was within the normal ranges.

In hepatic and renal function tests, significant changes were not observed in any group throughout the experiment.

Pathological examinations :

1) Organ weight and relative organ weight

Table 6 and 7 showed the results of organ weight and relative organ weight at the 39 week in the experiment.

Cerebellum weight was slightly increased in females of the $2.5 \mathrm{mg} / \mathrm{kg} / 2$ weeks group, although no significant change was observed in the relative cerebellum weight.

2) Gross autopsy findings

In the 39 week autopsy groups, accumulation of the tested compound in the synovial tissue and joint capsule (Photo 1) with dose-dependency was observed in the knee joint of all the groups treated with THS-201. Dotty hemorrhage, mucilagenous articular fluid without dose-dependency were observed in the knee joint of some male and female dogs treated with THS-201. Moreover, a female dog (animal No.10019) in the $2.5 \mathrm{mg} / \mathrm{kg} / 2$ weeks group showed the dislocation of patella, and erosion of cartilage layer on patella and medial ridge of femur.

At the objection site of the knee joint, a female dog (animal No. 10013) in the $0.5 \mathrm{mg} / \mathrm{kg} / 2$ weeks group showed the dislocation of patella, and it had shallow facies patellaris.

As to general organs, slight changes without dose-dependency were variously observed in the 39 week autopsy groups, and were very common changes in dogs.

In the 52 week autopsy groups, the gross findings at the injection site and in the general organs similar to the 39 week autopsy groups were observed. Moreover, all females $(2 / 2$ heads) of the $2.5 \mathrm{mg} / \mathrm{kg} / 2$ weeks group showed the erosion of the medial or the lateral ridge of femur, and one of these (animal No. 10024) showed an exposure of bone materials (Photo 2).

A male dog of the $0.5 \mathrm{mg} / \mathrm{kg} / 2$ weeks group showed the accidental hemorrhagic cystitis and contracted kidneys: the abnormalities in urine (positive in occult blood), biochemical changes in blood (increment of urea nitrogen and creatinine) and organ weight (decrement of left kidney in absolute and relative weight and increment of urinary bladder in absolute and 
Kazumasa YAMASHITA et al.




Toxicity study of halopredone acetate in dogs




Kazumasa YAMASHITA et al.

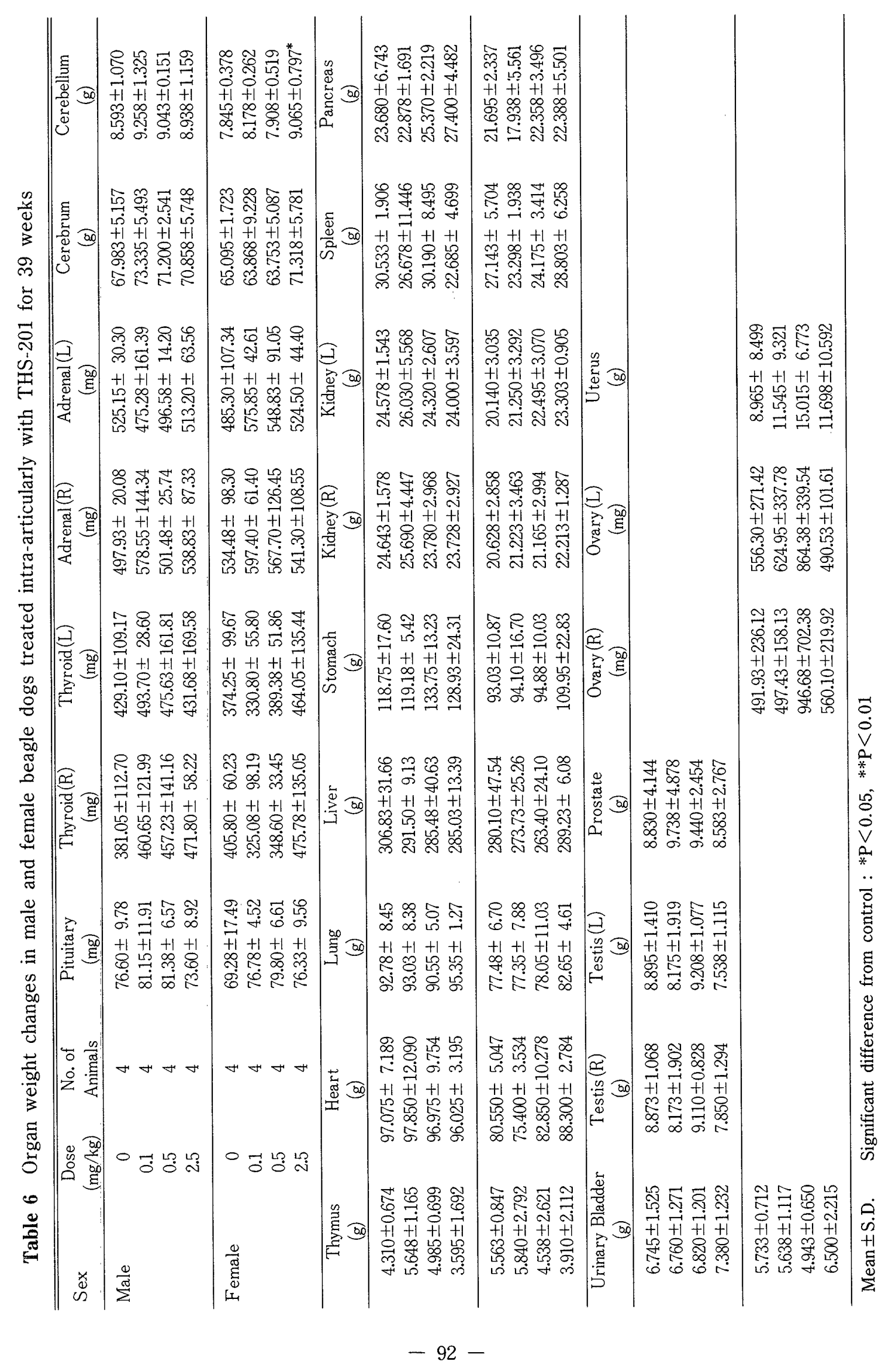


Toxicity study of halopredone acetate in dogs

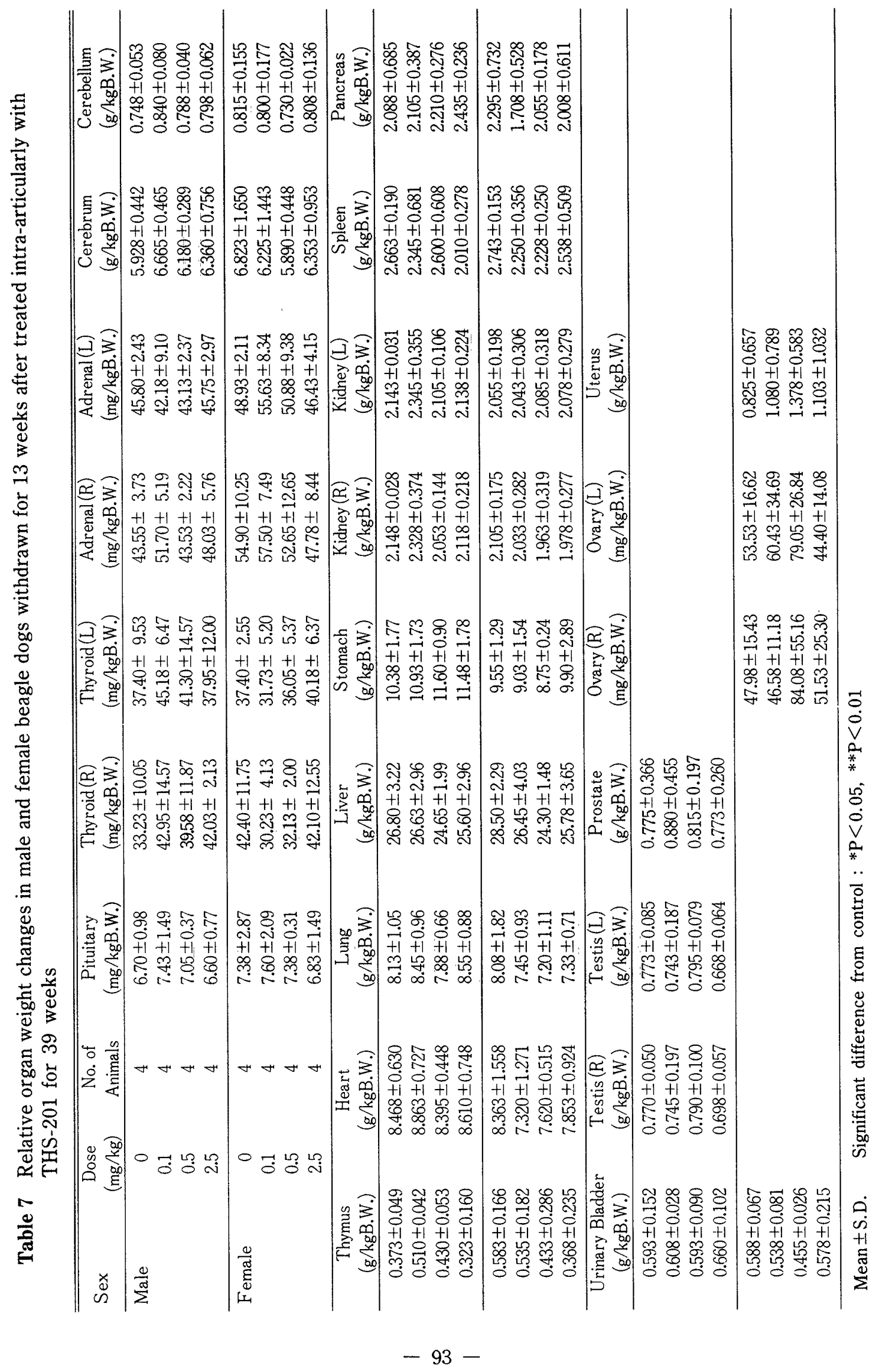




\section{Kazumasa YAMASHITA et al.}

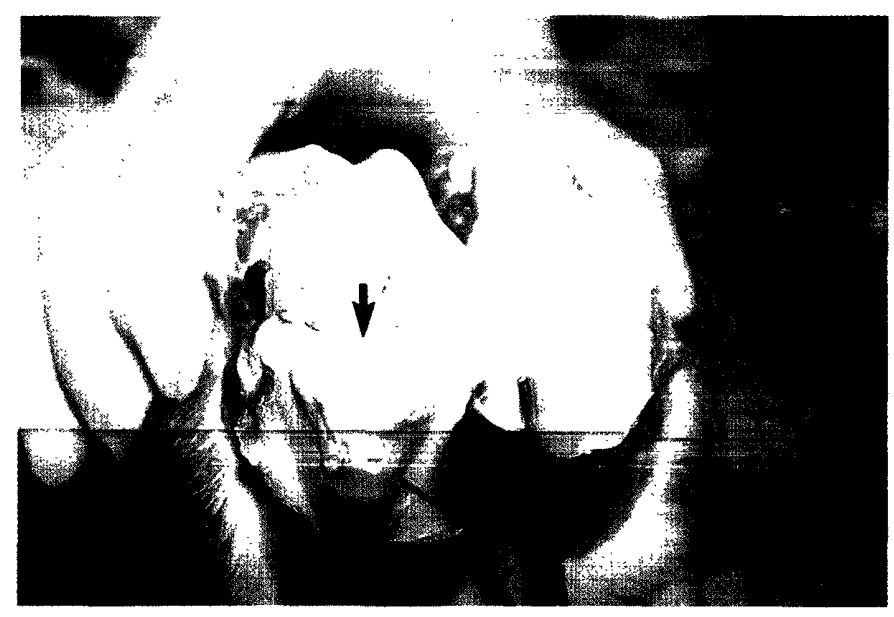

Photo 1 Knee joint: Accumulation of tested compound (Right knee $\downarrow$ ). No significant changes (Left knee) were observed. THS-201 $2.5 \mathrm{mg} / \mathrm{kg} / 2$ weeks, male, 00019 .

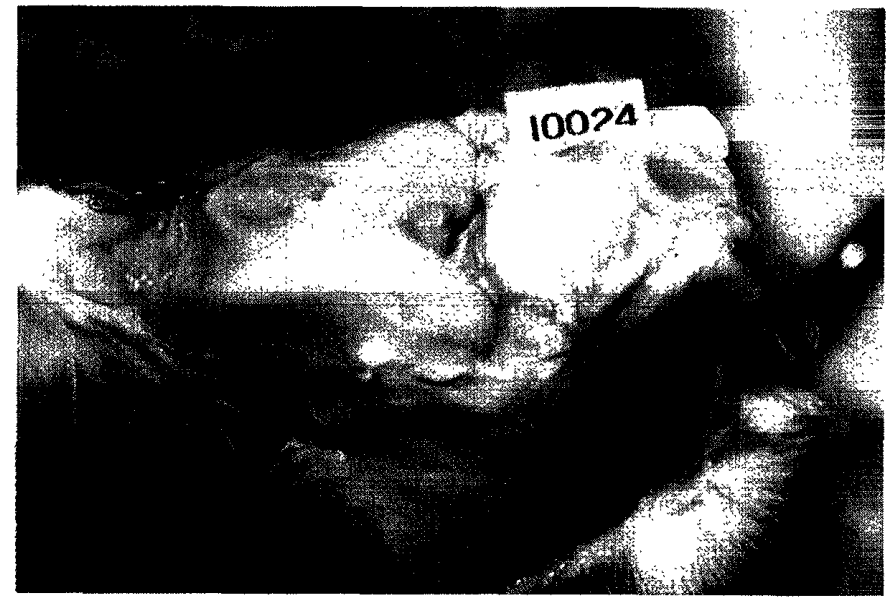

Photo 2 Knee joint (Right): Erosion of medial ridge and patella, accumulation of tested compound in synovial tissue and joint capsule. THS-201 $2.5 \mathrm{mg} / \mathrm{kg} / 2$ weeks, female, 10024 . 
Toxicity study of halopredone acetate in dogs

relative weight).

3) Light microscopy

Table $8,9,10$ and 11 showed the results of the histopathological examination on the knee joint.

In the 39 week autopsy groups, accumulation of the tested compound with dosedependency, slight swelling of the lining cells and the calcification surrounding the tested compound accumulated (Photo 3) were observed in all the groups treated with THS-201. Moreover, all males (4/4 heads) and 2 females of the $2.5 \mathrm{mg} / \mathrm{kg} / 2$ weeks groups showed the atrophy of skinny appendages, and some of these showed the atrophy of dermis (Photo 4 and 5). The cartilage matrix in articular cartilage and meniscus of knee joint in these groups showed the lesser stain of both H. E. and Safranine-0 stain (Photo 6 and 7). A female dog (animal No. 10019) attending the dislocation of the patella, showed the focal loss of cartilage layer on the patella and medial ridge of femur, and also showed the focal fibrosis in the medial ridge (Photo 8).

In addition, some dogs of the 0.1 and $0.5 \mathrm{mg} / \mathrm{kg} / 2$ weeks groups showed the synovitis, deposition of hemosiderin, and dotty hemorrhage in synovial tissue and joint capsule, and / or atrophy of skinny appendages in the injection site without dose-dependency. Cellular infiltration consisting mainly of foamy macrophages in synovial tissue and joint capsule were observed in all dogs of the control and the treated groups.

Concerning the general organs, slight changes were variously observed in the 39 week autopsy groups, though these changes were not dose-dependent: Such changes were very commonly observed in dogs.

In the 52 week autopsy groups, histopathological changes on the knee joint and the general organs similar to the 39 week autopsy groups were observed.

4) Electron microscopy

(1) SEM

In the 39 week autopsy groups, any changes of cartilaginous surface in both sexes of the $2.5 \mathrm{mg} / \mathrm{kg} / 2$ weeks groups (Photo 9 and 10 ) were hardly observed.

In the 52 week autopsy groups, any changes in males of the $2.5 \mathrm{mg} / \mathrm{kg} / 2$ weeks group were hardly observed in comparison with the control group. In all females( $2 / 2$ heads) of the $2.5 \mathrm{mg} / \mathrm{kg} / 2$ weeks group, the irregular cartilaginous surface, decrement of matrix substances and exposure of collagen fibers on cartilaginous surface were observed.

(2) TEM

In the 39 week autopsy groups, irregular thickness and elongation of collagen fibers, roughness of fibrous density and decrement of proteoglycans in cartilage matrix (Photo 11 and 12) were observed in the $2.5 \mathrm{mg} / \mathrm{kg} / 2$ weeks group, while any significant changes were not 
Kazumasa YAMASHITA et al.

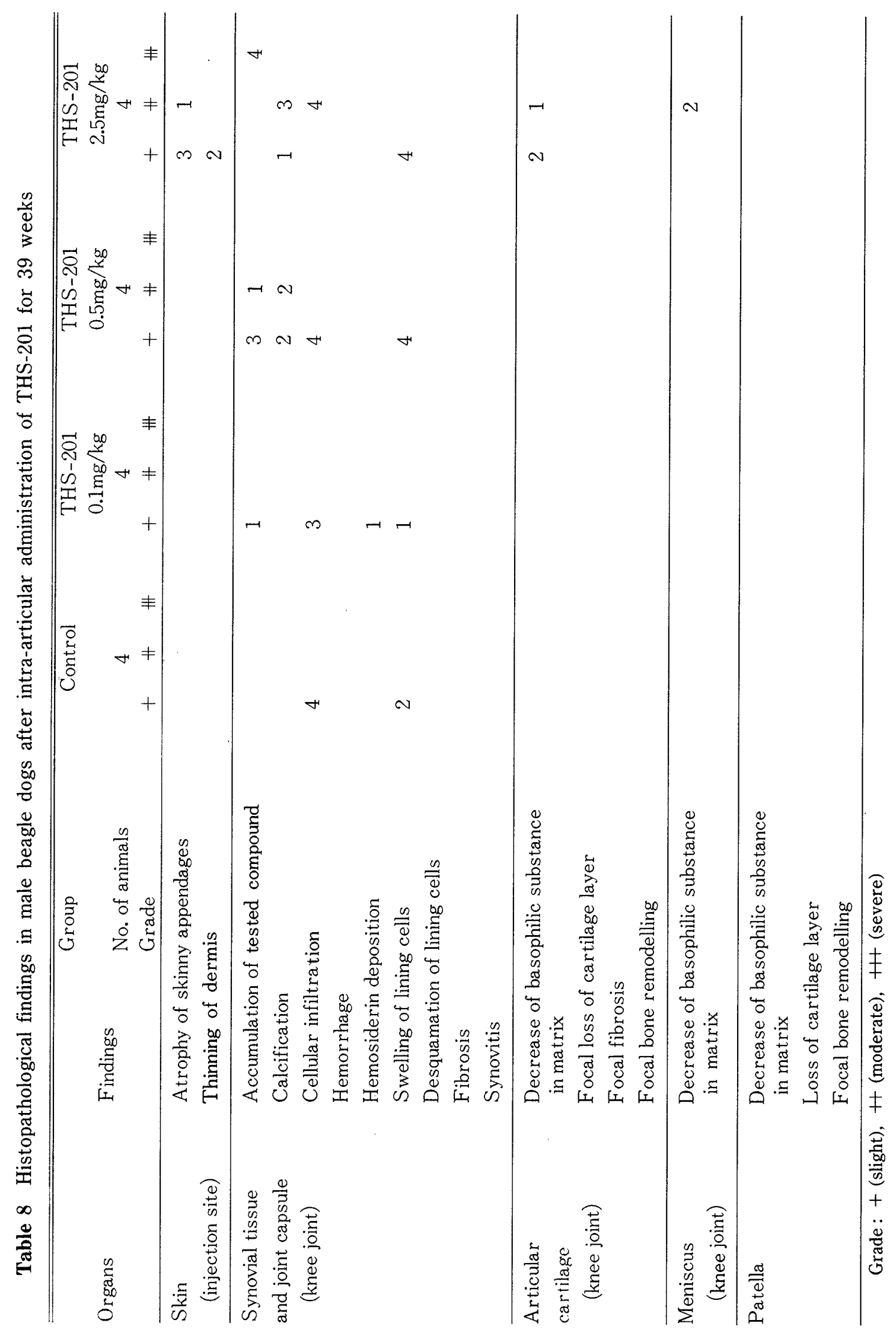


Toxicity study of halopredone acetate in dogs

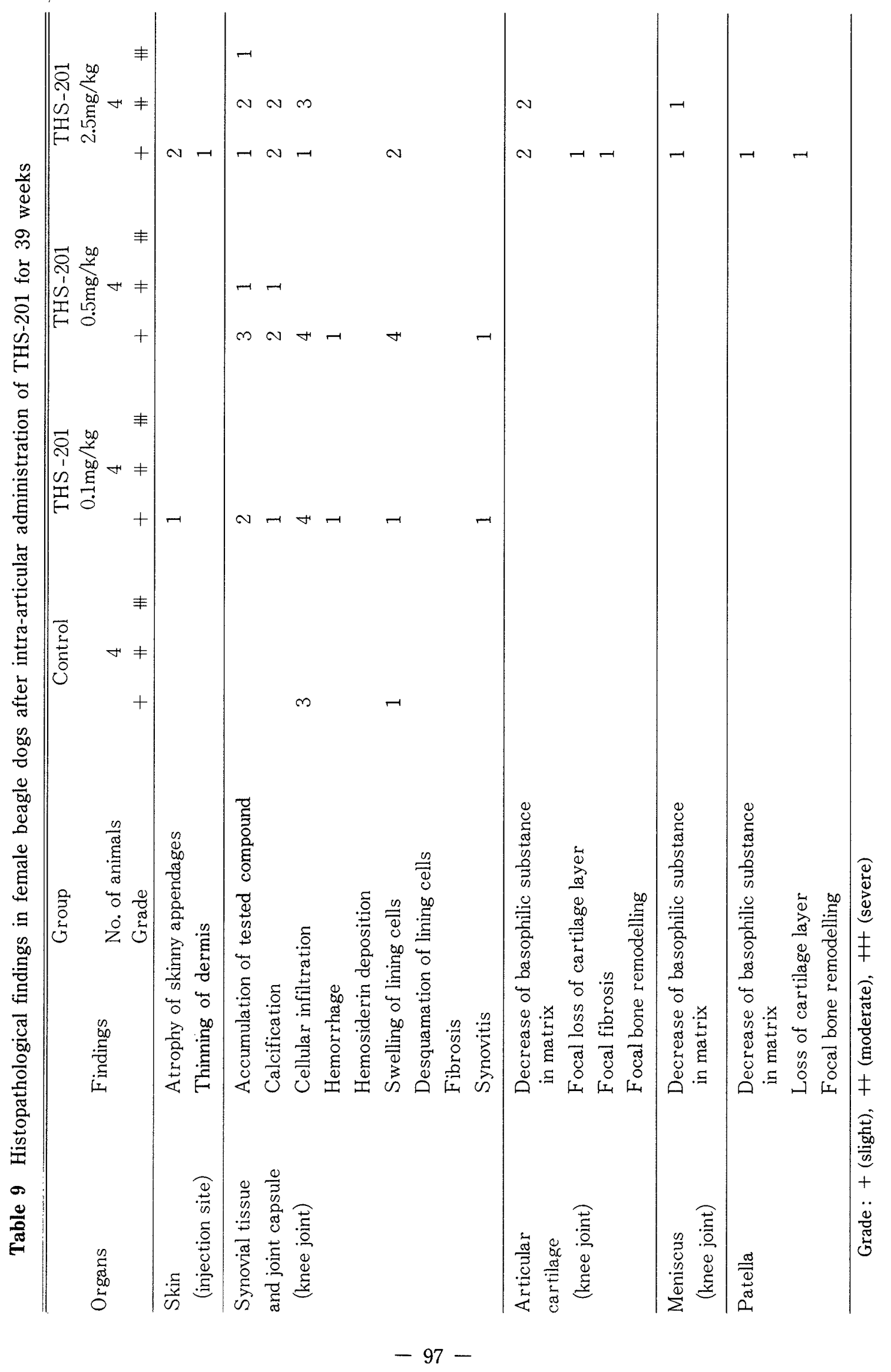


Kazumasa YAMASHITA et al.

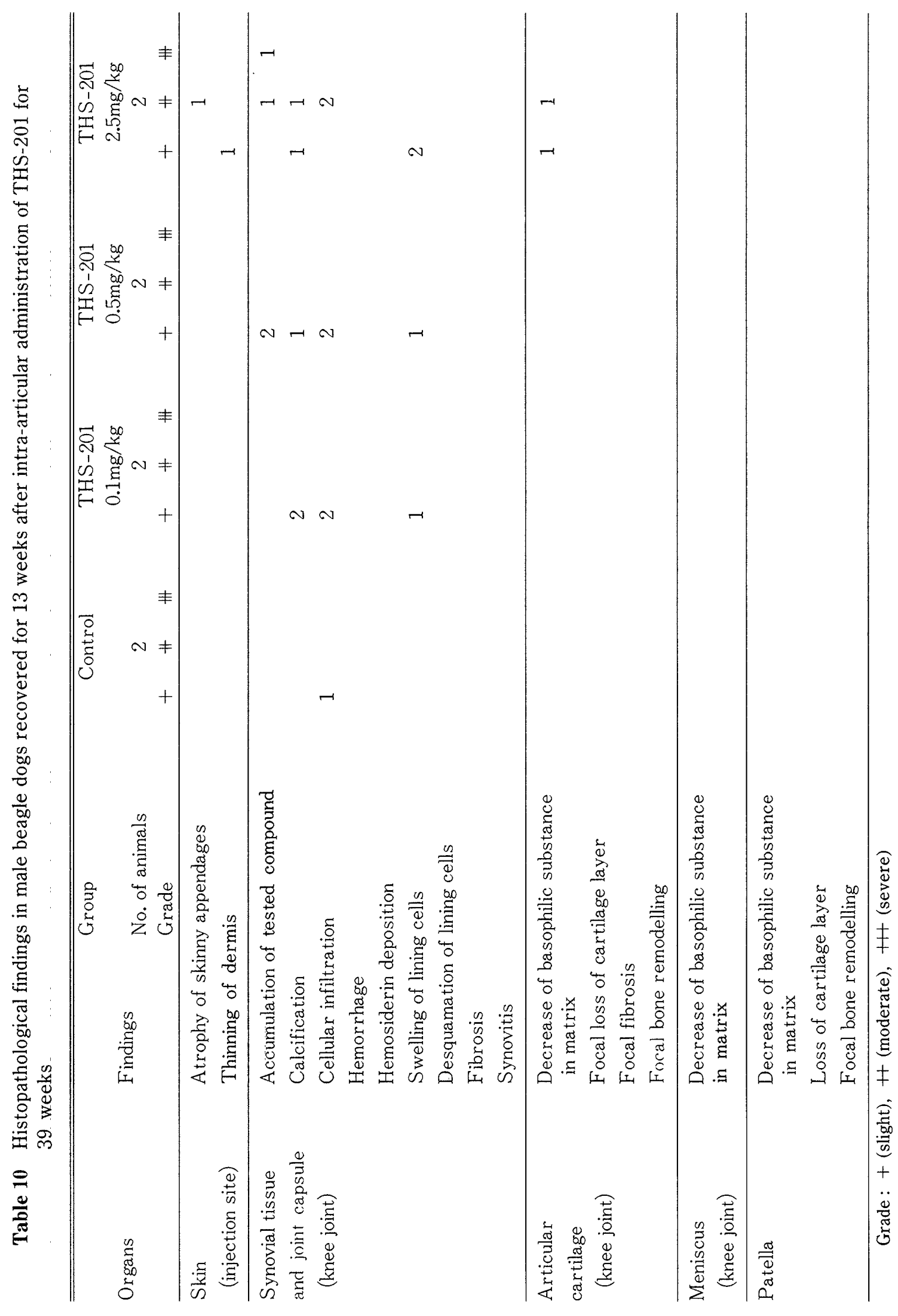


Toxicity study of halopredone acetate in dogs

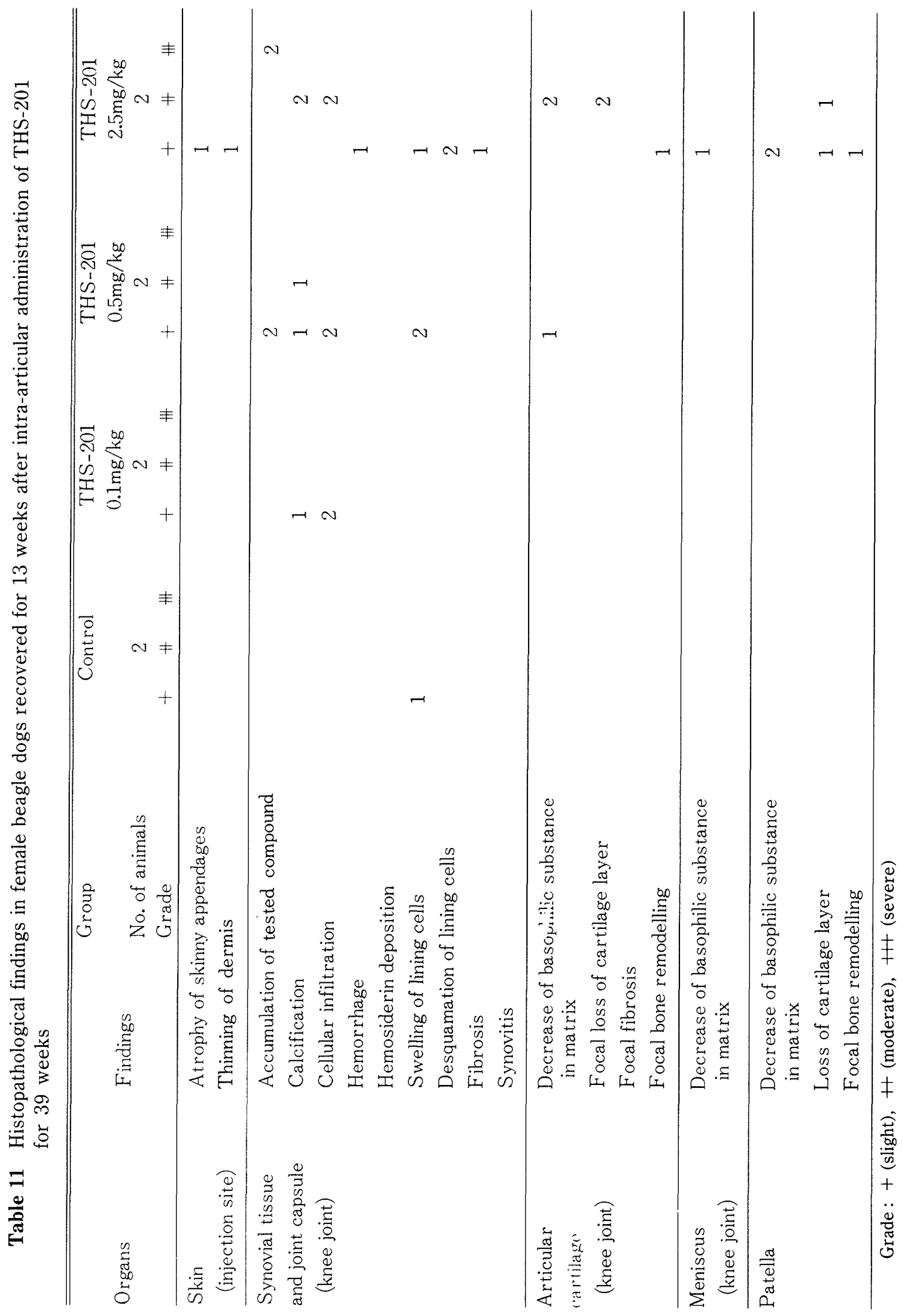


Kazumasa YAMASHITA et al.

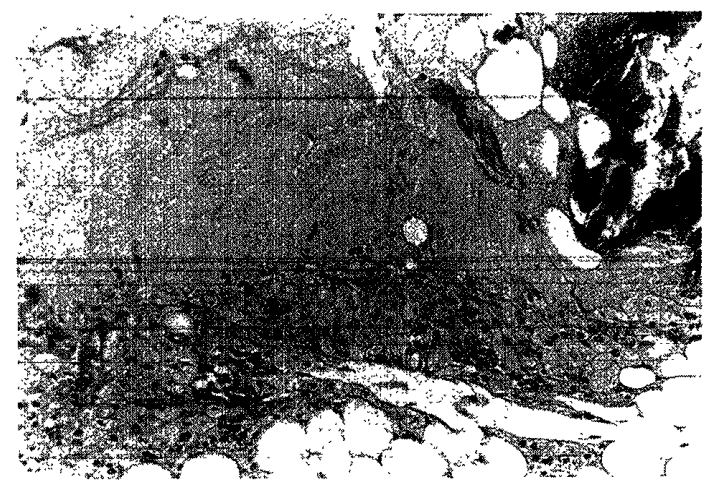

Photo 3 Synovial tissue and joint capsule (Right knee joint): Deposition of tested compound, calcification and cellular infiltration. THS-201 $2.5 \mathrm{mg} /$ $\mathrm{kg} / 2$ weeks, female, 10021 . H.E., $\times$ 150.

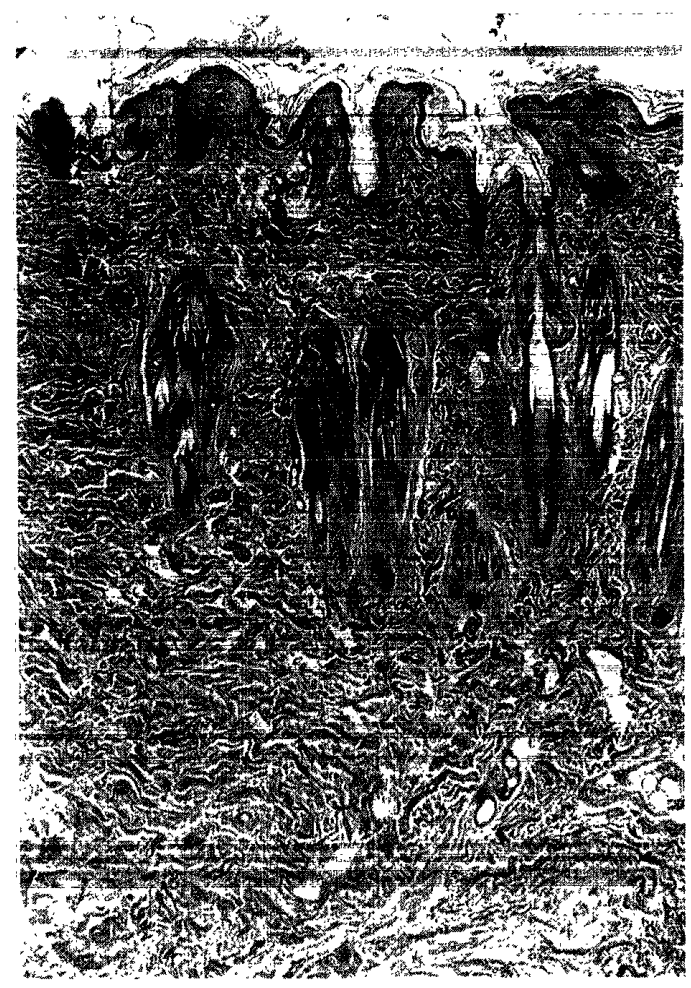

Photo 5 Skin (Injection site) : Atrophy of skinny appendages and dermis. THS-201 $2.5 \mathrm{mg} / \mathrm{kg} / 2$ weeks, female, 10020 . H.E., $\times 30$.

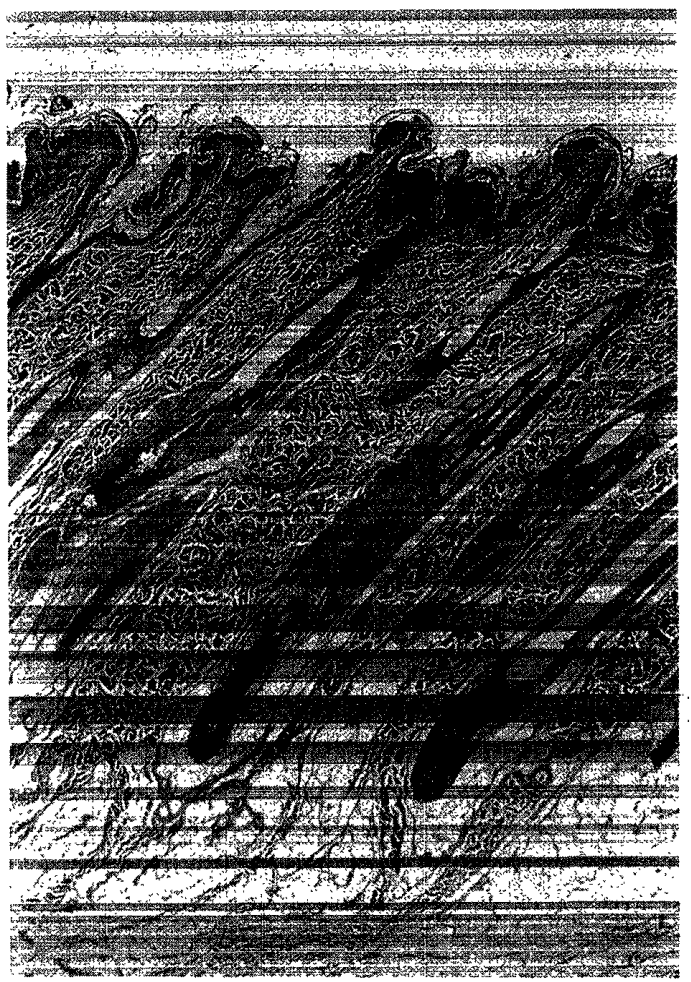

Photo 4 Skin (Injection site): No significant changes were observed. Control, female, 10001. H.E., $\times 30$.

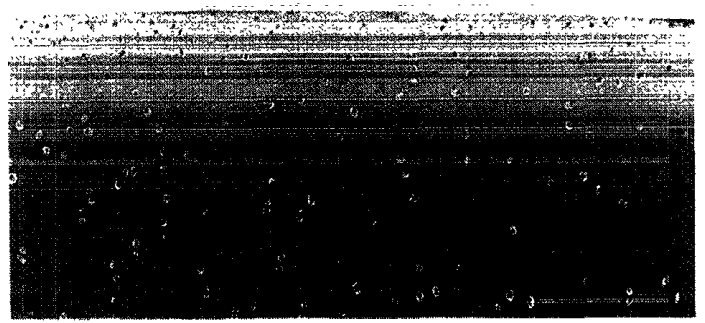

Photo 6 Articular cartilage (Right knee joint): No significant changes were observed. Control, female, 10003. Safranine-O stain, $\times 100$. 
Toxicity study of halopredone acetate in dogs

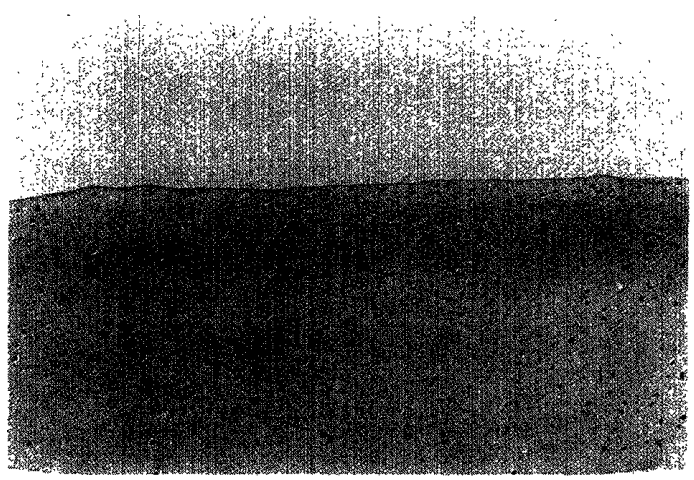

Photo 7 Articular cartilage (Right knee joint) : Lesser stain in cartilage matrix. THS$2012.5 \mathrm{mg} / \mathrm{kg} / 2$ weeks, male, 00021. Safranine-O stain, $\times 100$.

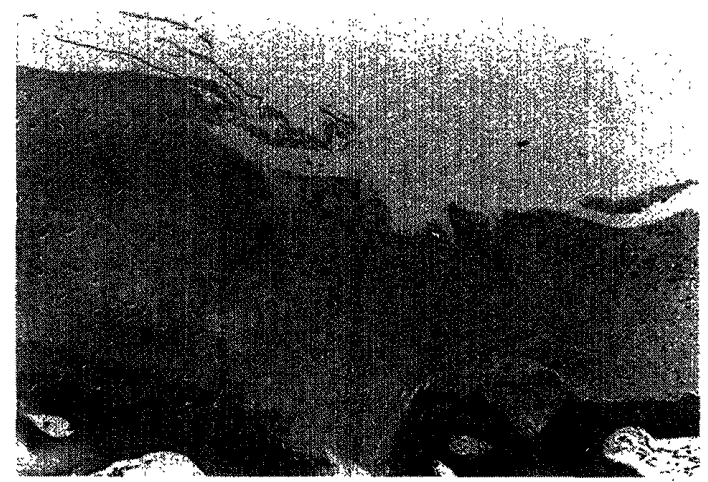

Photo 8 Medial ridge (Right knee joint) : Focal loss of cartilage layer, focal fibrosis and lesser stain in cartilage matrix. THS-201 $2.5 \mathrm{mg} / \mathrm{kg} / 2$ weeks, female, 10019. H.E., $\times 75$.

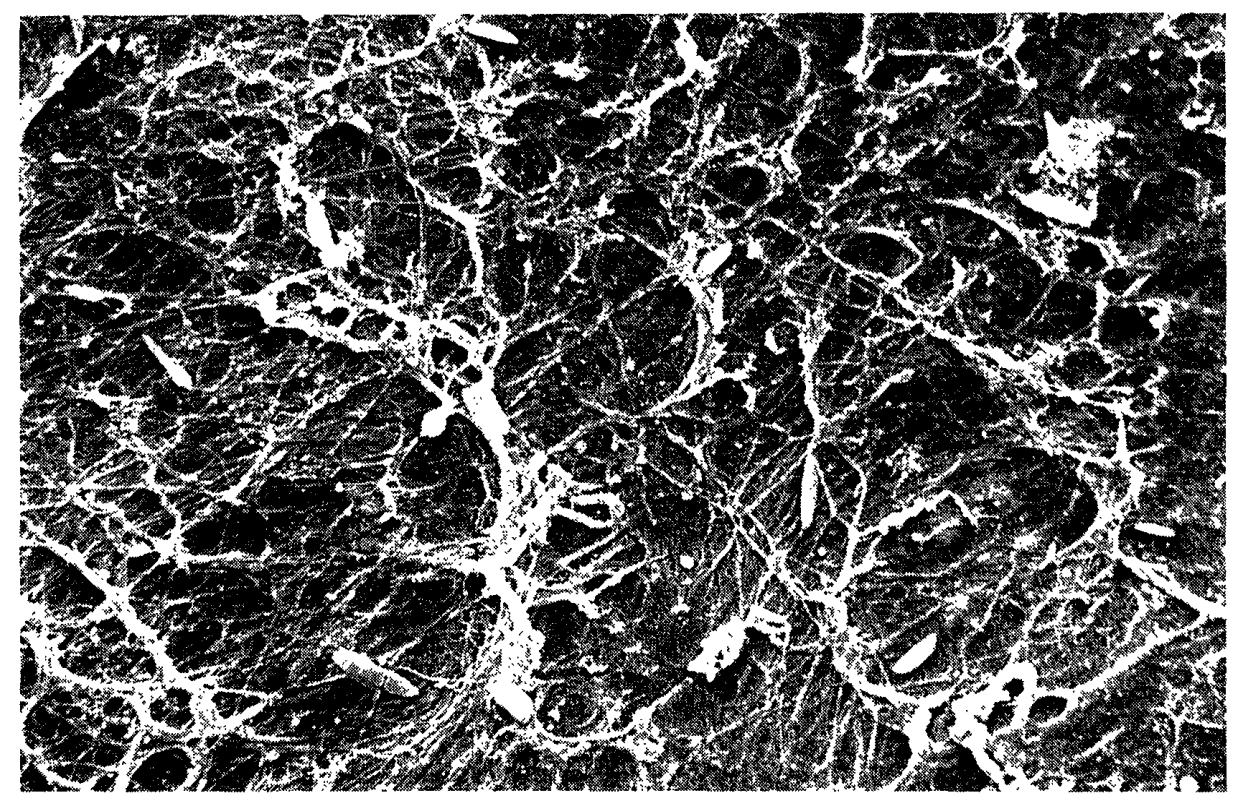

Photo 9 Cartilaginous surface (Medial condyle of right knee joint): Almost no changes. Control, female, 10003. $\times 9300,10 \mathrm{KV}$. 
Kazumasa YAMASHITA et al.

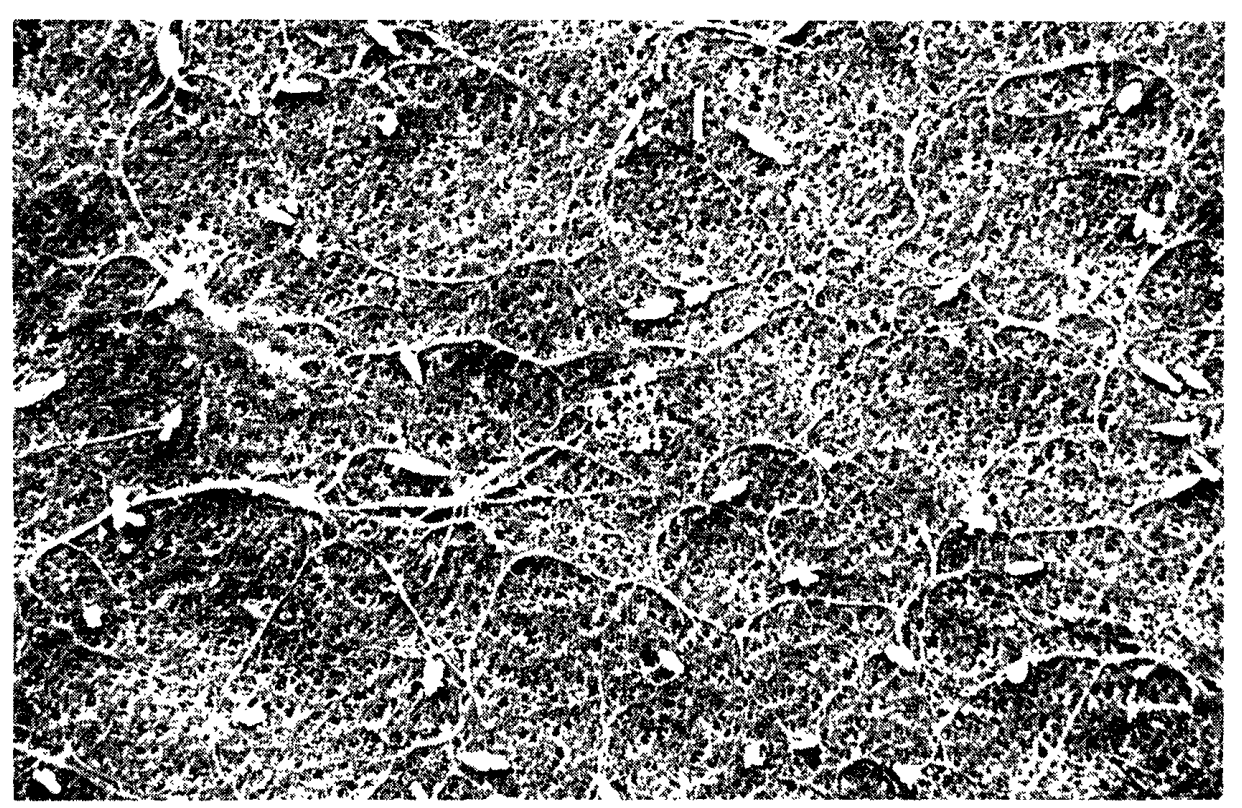

Photo 10 Cartilaginous surface (Medial condyle of right knee joint): Almost no changes. THS-201 $2.5 \mathrm{mg} / \mathrm{kg} / 2$ weeks, female, $10021 . \times 12500,10 \mathrm{KV}$.

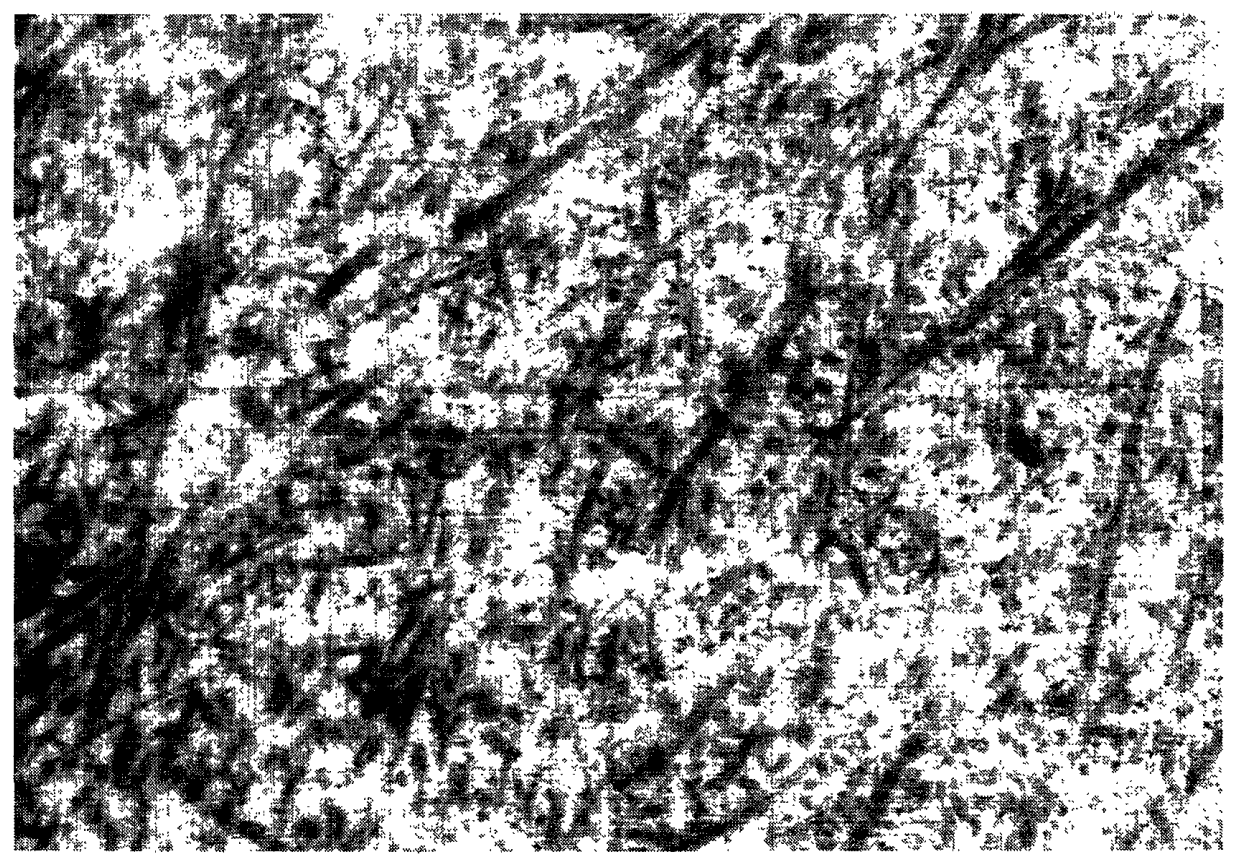

Photo 11 Articular cartilage (Medial condyle of right knee joint): Almost no changes. Control, male, 00003. Safranine-0, uranyl acetate and lead citrate stain, $X$ 40000 . 




Photo 12 Articular cartilage (Medial condyle of right knee joint): Irregular thickness and elongation of collagen fibers, roughness of fibrous density and decrement of proteoglycans. THS-201 $2.5 \mathrm{mg} / \mathrm{kg} / 2$ weeks, male, 00021 . Safranine), uranyl acetate and lead citrate stain, $\times 40000$.

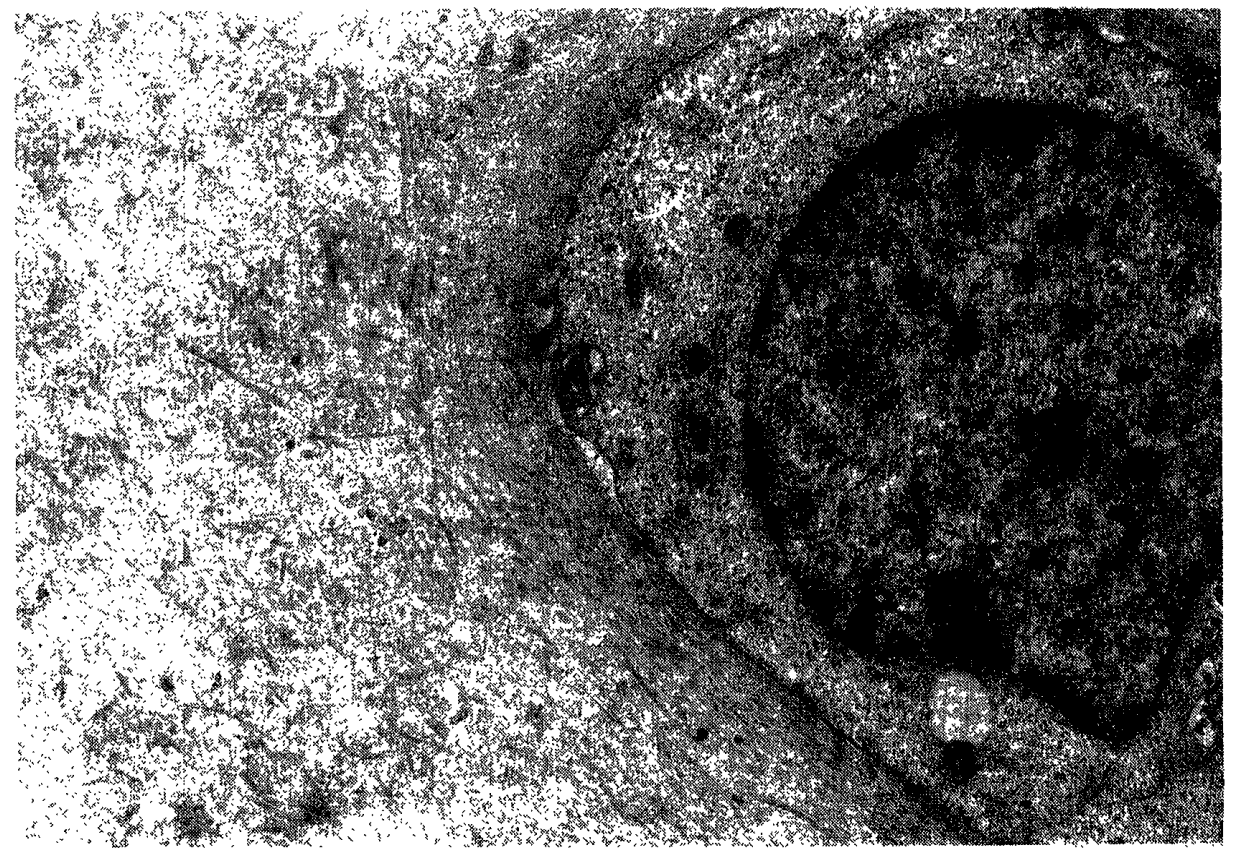

Photo 13 Chondrocyte (Medial condyle of right knee joint): Almost no changes. THS-201 $2.5 \mathrm{mg} / \mathrm{kg} / 2$ weeks, male, 00022. Safranine-0, uranyl acetate and lead citrate stain, $\times 8000$. 


\section{Kazumasa YAMASHITA et al.}

observed in condrocytes (Photo 13).

In the 52 week autopsy groups, changes similar to the 39 week autopsy groups were observed in articular cartilage.

No significant changes in liver and cortex of kidney were observed in the 39 and 52 week autopsy groups.

\section{DISCUSSION}

A fifty-two-week chronic intra-articular toxicity study of THS-201 was performed in both sexes of dogs.

In general conditions and symptoms, only the focal loss of hair at the injection site was observed in both sexes of the $2.5 \mathrm{mg} / \mathrm{kg} / 2$ weeks groups.

There were no significant changes on the body weight, food and water consumptions, ophthalmoscopic examination, ECG, urinary, fecal, hematological and biochemical, and hepatic and renal function tests. Although a male $\operatorname{dog}$ of the $2.5 \mathrm{mg} / \mathrm{kg} / 2$ weeks group showed the slight emaciation and slight decrement of body weight, it had no dose-related changes in terms of the pathological and various clinical laboratory examinations.

In the local pathological findings, the accumulation of tested compound in the synovial tissue and joint capsule were observed dose-dependently at the levels more than $0.1 \mathrm{mg} / \mathrm{kg} / 2$ weeks of THS-201. The below findings were observed in only the both sexes of the 2.5 $\mathrm{mg} / \mathrm{kg} / 2$ weeks groups: The loss of hair at the injection site accompanied with the atrophy of skinny appendages and dermis, the lesser stain of $\mathrm{H}$. E. in cartilage matrix of articular cartilage and meniscus with the lesser stain of Safranin-0 stain in the light microscopic examinations, and irregular thickness and elongation of collagen fibers, roughness of fibrous density and decrement of proteoglycans in the TEM examination. However, there were no morphological changes in condrocytes. In the SEM examination, there were no dose-related changes on the cartilaginous surface of the $2.5 \mathrm{mg} / \mathrm{kg} / 2$ weeks groups in the 39 and 52 week autopsy groups. Some of females of the $2.5 \mathrm{mg} / \mathrm{kg} / 2$ weeks groups in the 39 and 52 week autopsy showed the dislocation of patella. These changes were speculated to be caused by the smallness in joint cavity in females in comparison with males and also by the specificity of local accumulation of THS-201.

Moreover, the slight swelling of the lining cells, dotty hemorrhage, deposition of hemosiderin and cellular infiltration in / on the synovial tissue and joint capsule were observed in all dogs of the control and the treated groups. Also, the appearance of phagocytes, synovitis and the calcification surrounding the tested compound accumulated were observed in all the treated groups. These pathological changes have been reported in the previous paper (Yamashita et al., 1984) and were not accelerative adverse effects on the knee joint in 
Toxicity study of halopredone acetate in dogs

this study. Accordingly, it seemed that the changes in / on the synovial tissue and joint capsule were the phenomena ascribable to the biophylactic response to the foreign substances.

In general organs, only the common changes in dogs were observed in the 39 and 52 week autopsy groups, while these changes were not dose-related.

As mentioned above, some local changes, which were very similar to those of the 13-week subacute toxicity study in dogs, were observed in the $2.5 \mathrm{mg} / \mathrm{kg} / 2$ weeks group. Those changes suggested that THS-201 had slight effects to the cartilage matrix. However, the morphological changes of condrocytes were not observed in the light and electron microscopic examinations. Concerning the loss of hair at the injection site, it had not been observed in the 13-week subacute toxicity study in dogs, and had been observed from 6 months after the initiation of the treatment. Therefore, it seemed that the appearance of it was concerned with the administration period.

On the other hand, no systemic toxic signs were observed in this study. The authors (1984) reported that the phenomena such as the increment of leukocyte count and urine volume, atrophy of adrenal cortex and/or the infectious changes were observed in the intravenous toxicity study of THS-201 in dogs. These results were very similar to those of the study performed by Fielder et al. (1959) using various steroids in dogs. Accordingly, if the transition levels of THS-201 will be high into the blood from the injection site, the corticosteroid effects will be observed in the various organs, particularly in the adrenals and so on. The present authors (1985) also performed the local accumulation test of THS-201 in dogs which were administered intra-articularly at dose of $0.5 \mathrm{mg} / \mathrm{kg} / 2$ weeks under the same conditions as this study, and denoted that the blood level of THS-201 was not detected at the first and the final administration times: Only its metabolite was detected with a trace at the final administration time. These results suggested that THS-201 was excellent in point of the local accumulation, and had long-term anti-inflammatory effects and very weak systemic and local adverse effects.

In conclusion, on the basis of the local phenomena such as the biophylactic response to the foreign substances, it seemed that the non-effective dose level was less than $0.1 \mathrm{mg} / \mathrm{kg} / 2$ weeks, and that the effective dose to the joint cartilage was $2.5 \mathrm{mg} / \mathrm{kg} / 2$ weeks in both sexes.

In the systemic evaluation, it seemed that the non-effective dose level was $2.5 \mathrm{mg} / \mathrm{kg} / 2$ weeks, and toxic dose level was more than $2.5 \mathrm{mg} / \mathrm{kg} / 2$ weeks in both sexes : there was no sexual difference in dogs.

Therefore, it seemed that the administration of $0.5 \mathrm{mg} / \mathrm{kg}$ of THS-201 (intended therapeutic dose) at the regular intervals might be safety dose in the clinical use. 


\section{ACKNOWLEDGEMENT}

The authors are greatly indebted to Assistant Prof. R. Kanie, Department of Orthopaedic Surgery, Nagoya City University Medical School, for his helpful suggestions and supervision of the manuscript.

\section{REFERENCES}

Fielder, F. G., Hoff, E. J., Cronin, M. T. I. et al. (1959): A study of the subacute toxicity triamcinolone in dogs. Toxicol. Appl. Pharmacol., 1, 305-314.

Mizushima, Y., Miyake, H., Takikawa, K. et al. (1980): A highly topically active corticosteroid. Arzneim. Forsch., 30, 274-275.

Miyake, H., Fujiwara, K., Mizushima, Y. et al. (1981): Pharmacological effects of a synthetic corticoid F-2, having a marked locally residual activity. Japanese journal of inflammation, 1, (3), 407-411, spring.

Morimoto, H. (1979) : Treatment with steroid hormone and the practical use. Therapy, 2, (3), 360-364.

Shepard, N. and Mitchell, N. (1977) : The localization of articular cartilage proteoglycan by electron microscopy. Anat. Rec. 187, 463-475.

Toscano, L., Grisanti, G., Riva, M. et al. (1977) : Synthesis and topical anti-inflammatory properties of 17, 21-bis (acetyloxy)-6 beta, 9-difluoro-11 beta-hydroxy-pregna-1, 4-diene-3, 20-dione and related 2-halogenated compounds. J. Med. Chem. 20, 213-220.

Yamashita, K., Irimura, K., Morita, K. et al. (1984): Thirteen-week intra-articular súbacute toxicity study of Halopredon acetate and 8 week withdrawal study in dogs (unpublished).

Yamashita, K., Yada, H., Morita, K. et al. (1984): Three-week intravenous pre-subacute toxicity study of Halopredon acetate in dogs (unpublished).

Yamashita, K., Yada, H., Morita, K. et al. (1985) : The intra-articular local accumulation study of Halopredon acetate in male dogs (unpublished). 